\title{
Prediction of clinical outcome in patients treated with cardiac resynchronization therapy - the role of NT-ProBNP and a combined response score
}

\author{
Z. Bakos ${ }^{1,2^{*}}$ (D, N. C. Chatterjee ${ }^{2}$, C. Reitan ${ }^{1}$, J. P. Singh ${ }^{2}$ and R. Borgquist ${ }^{1}$
}

\begin{abstract}
Background: Cardiac resynchronization therapy (CRT) is an established therapy for appropriately selected patients with heart failure. Response to CRT has been heterogeneously defined using both clinical and echocardiographic measures, with poor correlation between the two.

Methods: The study cohort was comprised of 202 CRT-treated patients and CRT response was defined at 6 months post-implant. Echocardiographic response (E+) was defined as a reduction in LVESV $\geq 15 \%$, clinical response as an improvement of $\geq 1$ NYHA class $(C+)$, and biomarker response as a $\geq 25 \%$ reduction in NT-proBNP(B+). The association of response measures $(E+, B+, C+$; response score range $0-3)$ and clinical endpoints at 3 years was assessed in landmarked Cox models.

Results: Echo and clinical responders demonstrated greater declines in NT-proBNP than non-responders (median $[E+/ B+]$ : $-52 \%,[E+]:-27 \%,[C+]:-39 \%$ and $[E-/ C-]:-13 \% ; p=0.01$ for trend). Biomarker (HR $0.43[95 \%$ Cl: $0.22-0.86], p=0.02)$ and clinical (HR $0.40[0.23-0.70] p=0.001)$ response were associated with a significantly reduced risk of the primary endpoint. When integrating each response measure into a composite score, each 1 point increase was associated with a 31\% decreased risk for a composite endpoint of mortality, LVAD, transplant and HF hospitalization (HR 0.69 [95\% Cl: 0.50-0.96], $p=0.03$ ), and a 52\% decreased risk of all-cause mortality (HR 0.48 [95\% Cl: 0.26-0.89], $p=0.02$ ).

Conclusion: Serial changes in NT-proBNP are associated with clinical outcomes following CRT implant. Integration of biomarker, clinical, and echocardiographic response may discriminate CRT responders versus non-responders in a clinically meaningful way, and with higher accuracy.
\end{abstract}

Trial registration: The cohort was combined from study NCT01949246 and the study based on local review board approval 2011/550 in Lund, Sweden.

Keywords: Cardiac resynchronization therapy, Heart failure, Dilated cardiomyopathy, Cardiac response, NTproBNP

\footnotetext{
* Correspondence: zoltan.bakos@med.lu.se

${ }^{1}$ Department of Clinical Sciences, Arrhythmia section, Lund University, Skane

University Hospital, Lund, Sweden

2Division of Cardiology, Massachusetts General Hospital, Boston, USA
}

(c) The Author(s). 2018 Open Access This article is distributed under the terms of the Creative Commons Attribution 4.0 International License (http://creativecommons.org/licenses/by/4.0/), which permits unrestricted use, distribution, and reproduction in any medium, provided you give appropriate credit to the original author(s) and the source, provide a link to the Creative Commons license, and indicate if changes were made. The Creative Commons Public Domain Dedication waiver (http://creativecommons.org/publicdomain/zero/1.0/) applies to the data made available in this article, unless otherwise stated. 


\section{Background}

Cardiac resynchronization therapy (CRT) is a wellvalidated treatment for morbidity and mortality reduction in select patients with heart failure [1-4]. However, nonresponse to cardiac resynchronization therapy (CRT) continues to be a clinical challenge, and the cause is likely multifactorial [5]. It may involve one or several factors such as suboptimal left ventricular lead positioning, suboptimal device programming, myocardial scarring next to the pacing electrodes, absence of "correctable dyssynchrony" to start with, or aggravating concurrent comorbid conditions such as renal failure, iron deficiency and anemia [6-8]. Other comorbidities such as diabetes and the metabolic syndrome, have also been reported to have an influence on the clinical outcome of CRT results [9]. Using advanced CRT technology can offer improvement in this population [10]. Indeed, there is good evidence that a structured "non-responder" outpatient clinic may identify and address several of these issues, thereby likely improving the clinical outcome $[11,12]$. However, defining "positive response" has proven challenging, with heterogeneous definitions including echocardiographic and clinical response. In addition, correlation between echocardiographic and clinical response has been poor. [13, 14]. In this context, biochemical markers such as natriuretic peptides (for instance NT-proBNP) and micro-RNA have been shown to be associated with both clinical and structural measures in HF, and may help refine the classification of response to CRT and improve prognostication [15-17]. Heart failure leads affects the neuro-hormonal balance and induces changes on the molecular level. MicroRNA is a novel marker which may be associated with cardiovascular disease, such as arrhythmias or HF, and there are trials suggesting that CRT treatment induced reverse remodelling may be associated with reduction of the microRNA expression [17].

In this study however, we focused on examining the relationship between clinical, echocardiographic, and natriuretic peptide response to CRT. We then examined the association of an integrated response score with long-term clinical outcomes.

\section{Methods}

Four hundred and-ten consecutive patients eligible for CRT therapy were prospectively recruited from two tertiary referral centers; Massachusetts General Hospital in Boston, USA and Skane University Hospital in Lund, Sweden between 2011 and 2014. Of these patients nine died prior to follow up, and only 202 had paired echocardiographic, clinical, and biomarker data available; therefore 208 patients were excluded from further analysis. Patients with a class I or class II indication for CRT according to the guideline recommendations were included $[18,19]$. All patients underwent standard CRT implant procedure with transvenous leads. LV leads were positioned in the most favorable available anatomic branch of the coronary sinus (CS) that resulted in adequate lead stability with acceptable pacing parameters, without diaphragmatic stimulation. Mortality data was extracted from the Swedish national registry of death or from the United States Social Security Death Index. Clinical events including heart failure hospitalizations, heart transplantation, left ventricular assist devices (LVAD) and mortality were ascertained via chart review. Heart failure hospitalization was defined as an inpatient admission because of acute cardiac decompensation, with improvement of symptoms after adequate heart failure treatment. The primary endpoint was a composite of all-cause death, heart transplantation, left ventricular assist device (LVAD), and heart failure hospitalization. The study conforms to the Declaration of Helsinki, and the study protocols were approved by the respective Institutional Review Board and Ethics committee. All patients signed written informed consent prior to enrollment.

\section{Echocardiography}

The echocardiographic studies were performed with a standard imaging system (Vivid E9, GE Medical, Horten, Norway). Offline analysis was performed on a PC workstation with Echopac software (Echopac BT12, GE Medical, Horten, Norway). Standard echocardiographic assessment was performed in all patients preoperative and 6 month after the implantation. $\mathrm{ft}$. ventricular end-diastolic volume (LVEDV) and left ventricular end-systolic volume (LVESV) were measured, and left ventricular end systolic volume index was calculated (LVESVi).

\section{Definition of CRT response}

Echocardiographic response was defined as a reduction of LVESV $\geq 15 \%$ [20]. The clinical response was based on the New York Heart Association (NYHA) classification and was considered positive if the NYHA improvement was $\geq 1$ class [14] from pre-implant level. Dual responders were those individuals who had objective improvement on the echocardiography and at the same time the NYHA class improved with more than one class. Patients who did not fulfill definitions of clinical or echo response were classified as non-responders. NTproBNP was measured at baseline and at 6 months postimplant using standard commercial assays, and in paired analysis a $\geq 25 \%$ relative reduction of the baseline NTproBNP level was considered as a positive biomarker response.

\section{Statistical analyses}

SPSS statistical software was used for all data analysis (IBM corp. SPSS ver. 22, 2014). Continuous variables are 
expressed as mean (SD, standard deviation) or median (IQR, interquartile range) as appropriate, categorical variables are presented as frequencies and percentages. Differences between groups were assessed using Student ttests for continuous variables, Mann Whitney U test for variables with non-normal distribution, and the Fisher's exact test or $\mathrm{Chi}^{2}$ test or for categorical variables as appropriate. Paired T-test was used to compare echocardiographic dimensions from baseline to follow-up. The Wilcoxon paired Signed Rank test was used to assess changes in NT-proBNP levels and NYHA class. Cox regression analysis was used for prediction of the clinical endpoints, first in univariate analysis, and then in a pre-specified multivariate model adjusted for the clinically relevant co-variables age, sex, renal disease, ECG morphology and etiology of heart failure [21-23].

For identification of the proper cut off level of the relative NT-proBNP change, ROC analysis was performed in each subgroup. The goal was to identify a cut-off with highest possible sensitivity yet acceptable specificity, to differentiate the non-responders from responders. Survival analysis using the Kaplan-Meier method with log-rank test was used to analyze the cumulative events with a landmark set at 6 month, excluding all events prior to that. A two-sided $p$-value $<0.05$ was considered statistically significant.

\section{Results}

The participants -similarly to other randomized CRT trials- were dominantly male (78\%) in the age of 70's with ischemic CMP (50\%) and LBBB(64\%) with mean EF of $27 \pm 7 \%$. Baseline characteristics in details for the study cohort $(N=202)$ are shown in Table 1 . Over a median follow-up of 1133 (518 IQR) days, there were 48 patients who experienced at least one component of the composite endpoint, including 38 heart failure hospitalizations, 0 LVAD implantations, 0 transplants, and 25 deaths. Only $22 \%$ of patients were women, and there was no difference regarding clinical outcome or NT-ProBNP compared to male patients, however women were more likely to have a reduction of ESV $\geq 15 \%(p=0.04)$.

\section{Parameters for prediction of clinical outcome}

From baseline to 6 months, mean left ventricular ejection fraction increased from $27 \pm 7 \%$ to $34 \pm 9 \%$, LV endsystolic volume decreased from $158 \pm 69 \mathrm{ml}$ to $124 \pm$ $67 \mathrm{ml}$ and LV end-diastolic volume from $214 \pm 81$ to 183 $\pm 79 \mathrm{ml}$ (all $p<0.0001)$. Median NYHA class improved from 3 [IQR 1] (II-IV, 51/143/8) to 2 [IQR 1] (I-IV, 53/

Table 1 Study Population characteristics, stratified by BNP reduction $\geq 25 \%$, with $p$-value for difference between groups

\begin{tabular}{|c|c|c|c|c|}
\hline & All patients $(n=202)$ & BNP reduction $<25 \%(n=78)$ & BNP reduction $\geq 25 \%(n=124)$ & $P$-value \\
\hline Male gender & $157(78 \%)$ & $61(78 \%)$ & $96(77 \%)$ & 1.0 \\
\hline Age, (years) (median IQR) & $71(14)$ & $72(14)$ & $69(13)$ & 0.14 \\
\hline LV ejection fraction (mean \pm SD) & $27 \pm 7$ & $27 \pm 6$ & $27 \pm 8$ & 0.92 \\
\hline LVESV $($ mean \pm SD) & $158 \pm 68$ & $148 \pm 73$ & $164 \pm 65$ & 0.09 \\
\hline QRS duration (ms, median IQR) & $161 \pm 23$ & $154 \pm 23$ & $166 \pm 22$ & $<0.001$ \\
\hline Ischemic cardiomyopathy & $100(50 \%)$ & $38(49 \%)$ & $62(50 \%)$ & 0.89 \\
\hline Hypertension & $121(60 \%)$ & $47(60 \%)$ & $74(60 \%)$ & 1.0 \\
\hline Diabetes & $50(25 \%)$ & $21(27 \%)$ & $29(23 \%)$ & 0.62 \\
\hline Atrial Fibrillation & $91(45 \%)$ & $37(47 \%)$ & $54(44 \%)$ & 0.66 \\
\hline Previous CABG & $52(26 \%)$ & $22(28 \%)$ & $30(24 \%)$ & 0.62 \\
\hline LBBB & $129(64 \%)$ & $42(54 \%)$ & $87(70 \%)$ & 0.02 \\
\hline $\mathrm{LBBB}>150 \mathrm{msec}$ & $148(73 \%)$ & $46(59 \%)$ & $102(82 \%)$ & 0.01 \\
\hline NYHA class III-IV & $151(75 \%)$ & $55(71 \%)$ & $96(77 \%)$ & 0.32 \\
\hline ACEi or ARB use & $179(89 \%)$ & 69 (89\%) & $110(89 \%)$ & 1.0 \\
\hline Loop diuretic use & $147(73 \%)$ & $60(77 \%)$ & $87(70 \%)$ & 0.33 \\
\hline Anticoagulant use & $91(45 \%)$ & $34(44 \%)$ & $57(46 \%)$ & 0.77 \\
\hline Digoxin use & $27(13 \%)$ & $12(15 \%)$ & $15(12 \%)$ & 0.53 \\
\hline Beta-blocker use & $176(87 \%)$ & $65(83 \%)$ & $111(90 \%)$ & 0.28 \\
\hline Creatinine pre implant (mg/dl) & $1.12(0.45)$ & $1.20(0.52)$ & $1.08(0.44)$ & 0.05 \\
\hline CRT-D vs. CRT-Pacemaker & $169(84 \%)$ & $63(81 \%)$ & $106(86 \%)$ & 0.44 \\
\hline NT-proBNP baseline ( $\mathrm{ng} / \mathrm{L}$ median IQR) & 1554 (3393) & $1444(3770)$ & $1661(2968)$ & 0.31 \\
\hline
\end{tabular}


$113 / 35 / 1)(p<0.001)$. Reduction $\geq 15 \%$ of LVESV from baseline to follow-up occurred in $60 \%$ of patients, and was associated with a numerically lower hazard ratio for primary endpoint, although this reduced risk was not statistically significant (HR 0.65 [0.33-1.3], $p$ $=0.21$ ), nor for all-cause mortality; HR 0.92 [0.41-2. $0], p=0.83$. Results were similar if LVESV indexed for body surface area was used (LVESVi, data not shown). Improvement in NYHA class occurred in 135 patients (67\%), and was associated with a reduction in the hazard for the composite endpoint (HR 0.40 [0.23-0. $70], p=0.001$ ), and for all-cause mortality (HR 0.26 [0.12-0.60], $p=0.001)$.

In all there were 171 positive responders (51 clinical responders, 36 echocardiographic responders and 84 dual responders), and 31 non-responders who had neither clinical nor echocardiographic improvement. Baseline NTproBNP levels were similar between all groups (Table $1, p$ $=0.31$ ), and at 6 months there was an overall reduction from median 1554 [IQR 3393] to median 973 [IQR 2072], $p<0.001$. The positive responders (regardless of subgroup) had larger reduction in NT-proBNP levels than non-responders; dual responders $\Delta-52 \%$, clinical responders $\Delta-39 \%$, echo-responders $\Delta-27 \%$ and nonresponders $\Delta-13 \%$ ( $p=0.01$ for trend, see Fig. 1). By ROC analysis (Fig. 2), a 25\% reduction of NT-proBNP was shown to have $64 \%$ sensitivity and $56 \%$ specificity for prediction of freedom of the 3-year composite endpoint in the entire cohort. In Cox regression and Kaplan Meier analysis, NT-proBNP increase, or less than $25 \%$ reduction, at 6 months was associated with higher risk of death or heart failure hospitalization (HR 0.43 [0.22-0.85], $p=0.02$, see Fig. 2). Further ROC analyses (see Additional file 1: Figure S1) showed that including the variable for " $\geq 25 \%$ NT-ProBNP reduction" consistently increased the area

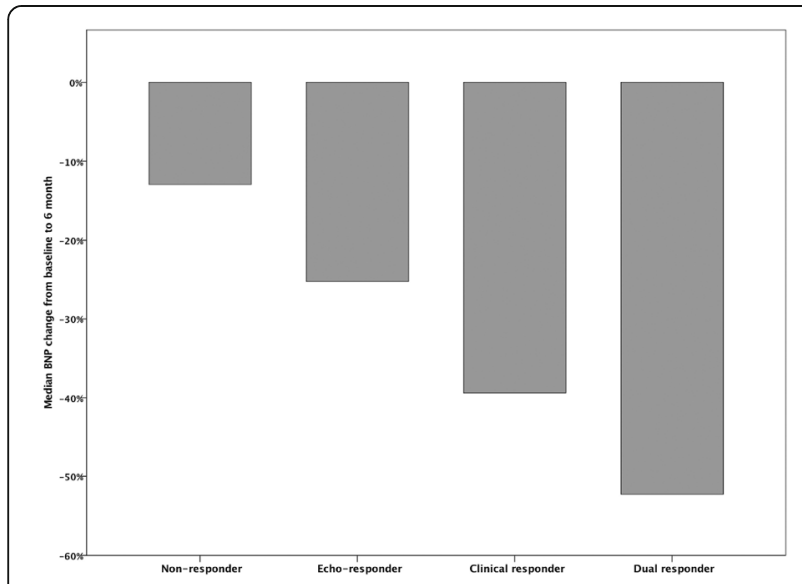

Fig. 1 BNP reduction from baseline to 6 months, stratified for echocardiographic or clinical response. $P$ values for comparisons; Clinical- vs non-responders: 0.029, Echo- vs non-responders:0.016, Double- vs non-responders: 0.011



Fig. 2 Kaplan Meier showing survival free of heart transplant and left ventricular assist device, stratified for BNP reduction $\geq 25 \%$

under the curve (AUC) for prediction of hard endpoints (mortality or a combination of heart failure hospitalization and mortality).

\section{"CRT response score"}

A composite "CRT response score" was constructed, incorporating one point each for positive clinical $(\geq 1$ NYHA class improvement), echocardiographic ( $\geq 15 \%$ LVESV reduction) and biomarker ( $\geq 25 \%$ reduction in NT-proBNP) response. This score had the highest AUC value in $\mathrm{ROC}$ analysis for both the combined endpoint (0.67) and for the all-cause mortality endpoint (0.74). Eighteen patients (9\%) had 0 points, 49 (24\%) had 1 point, 75 (37\%) had 2 points and $60(30 \%)$ had 3 points on the score. In both univariate and multivariate analysis, the total CRT response score was a significant predictor the primary composite endpoint, with an independent 39\% reduction of the risk of death or heart failure hospitalization for each additional point (HR 0.69 [0.50-0.96], $p=0.03$, see Table 2). For the secondary endpoint of all-cause mortality, in multivariate analysis each additional point of the score was associated with a $52 \%$ reduction of the risk of death within 3 years (HR 0.48 [0.26-0.89], $p=0.02$ ). In Kaplan Meier analysis the score was able to discriminate in particular between those patients with the lowest event-free survival ( 0 points), compared to patients with one or more points on the composite score who had a significantly better survival (see Fig. 3). For the all-cause mortality endpoint, those with $0-1$ points 
Table 2 Cox regression analysis with three-year survival free of heart failure hospitalization as endpoint

\begin{tabular}{|c|c|c|c|c|c|c|}
\hline & Univariate & & & Multivar & & \\
\hline & $P$-value & $\mathrm{HR}$ & 95\% C.I. & $P$-value & $\mathrm{HR}$ & 95\% C.I. \\
\hline Female gender & 0.12 & 0.44 & $0.15-1.2$ & 0.24 & 0.59 & $0.24-1.4$ \\
\hline Age, years (median IQR) & 0.03 & 1.04 & $1.0-1.08$ & 0.4 & 1.01 & $0.98-1.0$ \\
\hline Ischemic cardiomyopathy & 0.5 & 1.3 & $0.64-2.5$ & 0.33 & 1.4 & $0.71-2.8$ \\
\hline LV ejection fraction, (\%) & 0.67 & 0.99 & $0.94-1.04$ & 0.03 & 0.69 & $0.50-0.96$ \\
\hline Hypertension & 0.79 & 1.1 & $0.55-2.2$ & & & \\
\hline Diabetes & 0.34 & 1.4 & $0.69-3.0$ & & & \\
\hline History of atrial Fibrillation & 0.22 & 1.5 & $0.78-3.0$ & & & \\
\hline QRS duration & 0.32 & 0.99 & $0.98-1.0$ & & & \\
\hline Left bundle branch block & 0.1 & 0.57 & $0.29-1.1$ & 0.03 & 0.51 & $0.28-0.93$ \\
\hline ACEi or ARB use & 0.5 & 0.72 & $0.28-1.9$ & & & \\
\hline Loop diuretic use & 0.34 & 1.5 & $0.66-3.5$ & & & \\
\hline Beta-blocker use & 0.4 & 1.7 & $0.51-5.4$ & & & \\
\hline Creatinine pre implant & 0.49 & 1.1 & $0.83-1.5$ & & & \\
\hline CRT-P (compared to CRT-D) & 0.02 & 2.4 & $1.2-5.1$ & 0.21 & 1.6 & $0.78-3.2$ \\
\hline NT-proBNP baseline (per 100 ng/L) & 0.02 & 1.01 & $1.001-1.009$ & & & \\
\hline NYHA class baseline & 0.52 & 0.85 & $0.52-1.4$ & & & \\
\hline Composite score (per point) & $<0.0001$ & 0.52 & $0.36-0.74$ & 0.03 & 0.69 & $0.50-0.96$ \\
\hline
\end{tabular}

$C R T$ cardiac resynchronization therapy, $A C E i$ ACE-inhibitor, $A R B$ angiotensin receptor blocker, $C R T-D$ cardiac resynchronization therapy with defibrillator function, CRT-P cardiac resynchronization therapy without defibrillator function

"Multivariate model corrected for gender, age, LBBB, type of cardiomyopathy and type of CRT-device

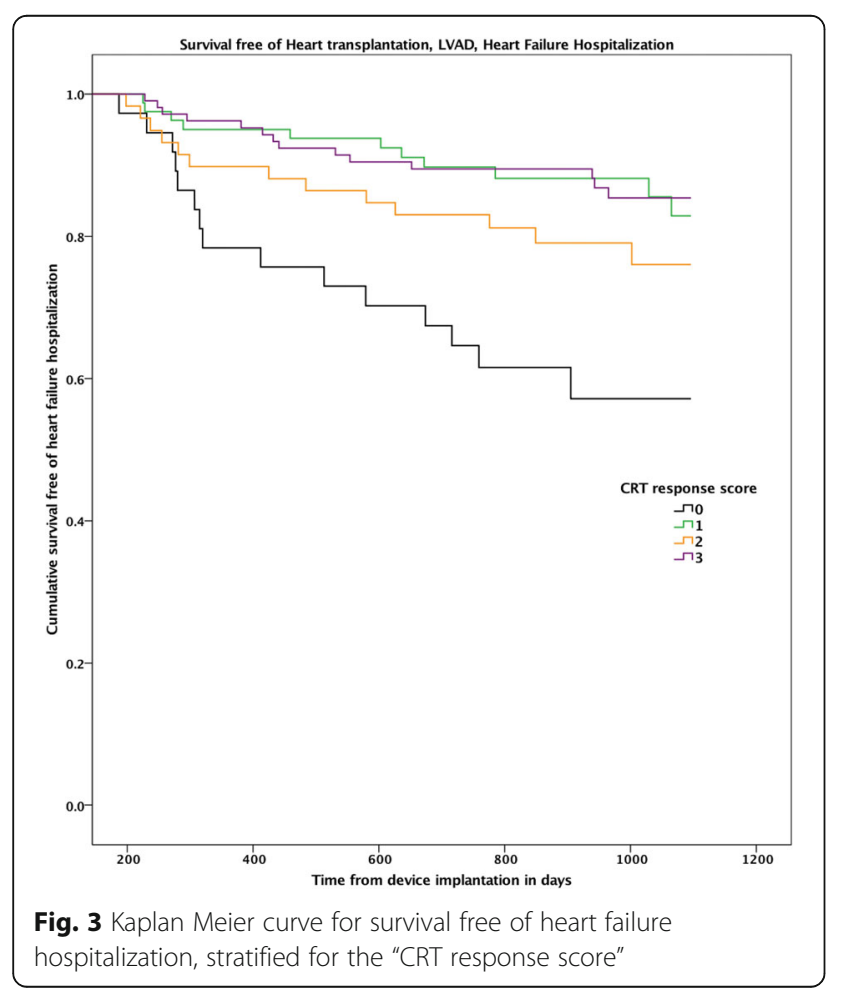

had significantly higher mortality than those with $2-3$ points (log rank $p=0.001$, see Fig. 4).

\section{Discussion}

In this prospective two-center cohort of consecutive CRT treated patients, we show that by combining echocardiographic, clinical and biomarker information into a simple $0-3$ point score, we were able to identify the patients with the highest risk of adverse clinical outcome. This may have implications for how to set up a structured follow-up of CRT implanted patients; by using the proposed simple scoring system, the clinician will be able to identify most patients with poor prognosis at the 6-months follow-up visit, thus enabling a more focused intervention to try to potentially convert these patients to responders and/ or improve their clinical outcome [24, 25].

\section{Echocardiography based parameters}

Several measures of "response" have been used in the randomized trials. The MADIT-CRT trial was the first to report more extensively on the effect of echocardiographic remodeling measures on subsequent clinical outcome $[26,27]$. The authors showed that end-systolic volume, end-diastolic volume and LVEF were all correlated to decreased hazard of the long-term composite clinical endpoint (with the same magnitude of hazard 
Survival free of Heart transplantation, LVAD, Heart Failure Hospitalization

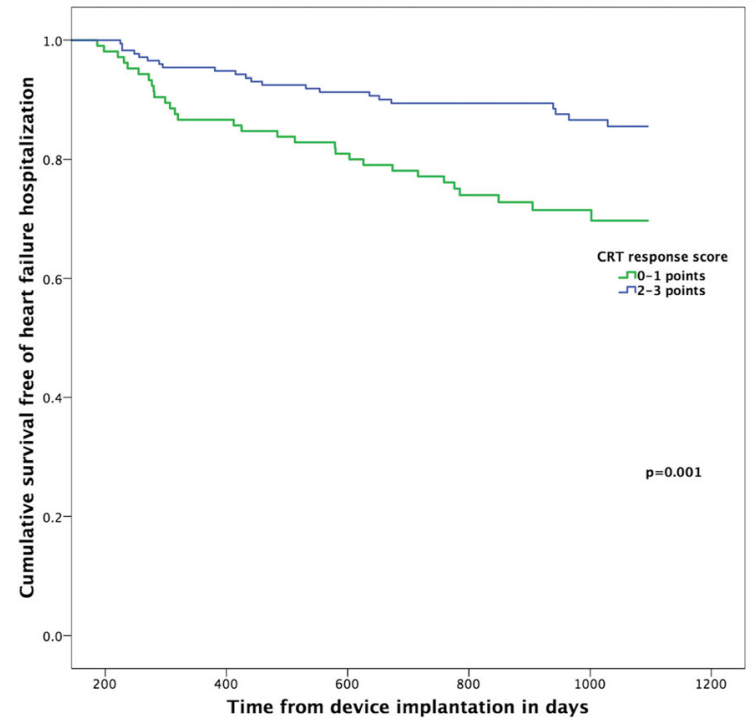

Fig. 4 Kaplan Meier plot for survival, stratified for the "CRT response score" (0-1 points vs. 2-3 points)

ratio from $0.60-0.72$ for a $10 \%$ relative decrease in volume or a $5 \%$ absolute increase in LVEF). The REVERSE study showed similar results with a $14 \%$ hazard reduction of 5-year mortality for every $10 \%$ decrease in LVESV-index, and a 68\% risk reduction for a dichotomized endpoint of LVESVi decrease $\geq 15 \%$ [28]. On the contrary, our results from the present non-randomized observational cohort do not show a strong correlation between echocardiographic remodeling and clinical outcome. This may be due to reduced statistical power because of relatively few patients in the study, since the non-significant hazard ratio of 0.65 was of similar magnitude as in the randomized trials, and indicated a trend in the same direction. Since the established correlation between reverse remodeling and later reduction in clinical endpoints is strong, this prompted us to keep the echocardiographic evaluation in the final composite score. As was seen in the REVERSE trial, it may take longer for the CRT induced remodeling evident at 6 months post-implant to have an effect on actual clinical outcome [29, 30].

\section{Clinical improvement}

The "Packer clinical score" has been used in several CRT studies and other studies on heart failure patients, and has been shown to correlate with clinical outcome [31]. The most widely used definition in the early CRT studies was improvement in NYHA class $\geq 1$ from baseline to follow-up [32, 33], but other subjective patient-based evaluations have also been shown to correlate to clinical outcome [34]. The evaluation of clinical status is prone to placebo-effect on the part of the patient, and has its limitations with regards to inter-individual reproducibility on the part of the physician. However, it is an important factor in the follow-up for CRT treated patients, since many patients (and physicians) would be unwilling to make major changes to an ongoing treatment when the patient experiences a definite improvement compared to the pre-operative status. In line with many previous studies, we show that improvement in NYHA class is strongly associated (HR 0.21 for all-cause mortality and HR 0.53 for the composite endpoint) to better clinical outcome, and an important parameter in the comprehensive clinical evaluation of CRT response.

\section{Role of NT-ProBNP}

BNP and NT-proBNP levels are increased in HF, and correlate well with ventricular wall stress and severity of HF. Elevation of these peptides has a wellestablished role for prediction of mortality for both acute and chronic heart failure situations [35, 36]. In the CRT setting, the evidence for baseline BNP levels to predict clinical outcome is ambiguous; higher levels of BNP pre-implant have been correlated to higher risk of 1 year adverse events post-implant by some investigators [37, 38], but other studies have not shown any correlation of baseline BNP to CRTresponse [39]. Most likely this is due to the fact that successful CRT treatment can occur regardless of baseline BNP levels, and depends on a number of factors unassociated with baseline BNP levels, hence the resynchronization effect (and clinical outcome) is hard to predict by this metric. However, a decrease in BNP or NT-proBNP has consistently been showed to correlate with successful resynchronization and improvement of heart failure symptoms in CRT trials [40-42]. In those with longer follow-up times, this BNP reduction also transformed into reduced risk of adverse events and mortality [43, 44]. In the MADITCRT trial, patients who received CRT-T and at 1 year post-implant had reduced BNP-values (or low values at baseline that remained unchanged at follow-up), had significantly lower risk of subsequent heart failure hospitalization or death [15]. In the present study we found that BNP levels were significantly reduced in responders (echo- or clinical) compared to non-responders, and that the greatest reduction was seen in those patients who exhibited both a clinical and echocardiographic positive response. In contrast, patients who did not respond on any of these three parameters, had a poor prognosis with significantly higher mortality and heart failure hospitalizations. A cutoff of $25 \%$ reduction in BNP was associated with better clinical outcome, and proved to be useful in combination with the other parameters in the CRT response score. However, the sensitivity and specificity were not good enough for a specific cut-off value for NT- 
ProBNP reduction to be used as a stand-alone criterion for accurate prediction of clinical outcome.

\section{Clinical utility of the CRT response score}

The combined score had an independent predictive value for clinical outcome; each additional point of the score was associated with a $52 \%$ reduction of the risk of death within 3 years (HR 0.48 [0.26-0.89], $p=$ 0.02 ), but for practical purposes the major prognostic difference was for those patients who did not fulfill any of the three response criteria. This was visible in Kaplan Meier analysis where there was a clear separation of the patients with zero points compared to patients with one or more points regarding mortality and hear failure hosopitalization outcome. Indeed, the minority group of patients with zero CRT response score points had an event-free 3-year survival of less than $60 \%$, and therefore could potentially benefit from intensified care or even reoperation in case of suboptimal CRT effect. Assessing clinical response to CRT can be challenging, especially when having the placebo effect in mind. Using a natriuretic peptide for a more objective evaluation of decompensated left ventricular function can therefore be helpful. Thus, adding an NT-proBNP test to the preoperative and post-implant evaluation is an inexpensive tool that has the potential to aid the clinician in making an informed decision on which patients have a poor prognosis and need to be more thoroughly evaluated. Our findings add to the present evidence for the important role of dynamic changes in BNP /NT-proBNP in relation to clinical outcome in CRT.

Other factors, including diabetes and gender, have by some been suggested as prognostic factors in CRT treated patients, but analyses in our cohort showed no significant difference in prognosis for these parameters, and our results are in line with previous data suggesting that diabetes and gender do not limit CRT response [45].

\section{Limitations}

This study included a limited number of patients, from two tertiary care institutions. Even though the baseline demographics indicate that the patient cohort is similar to most of the previously published studies, there may be a selection bias compared to the general "real life" CRT patients seen at other non-tertiary referral implanting centers. The echocardiography data were analyzed at two different locations, and there may be differences between the echocardiography readings that are not accounted for. Data on LV electrode position, and \% of biventricular pacing post-implant were not included in the analysis, but every effort was made to ensure $\geq 95 \%$ biventricular pacing, and the implanting physicians uniformly targeted the LV lead placement in a lateral or posterolateral position with long electrical delay (measured as interlead RV-LV delay). Furthermore, the implants took place prior to the widespread use of quadripolar leads, and only one patient in the cohort had a quadripolar lead implanted. This may have influenced the proportion of CRT responders negatively. Echocardiographic optimization was performed at the patients in one of the two institutions, whereas the other institution used an EGM-based optimization (Quickopt ${ }^{\circ}$ ) built into the device as standard, a method which has been validated and found similar to echocardiography-based optimization [46]. This may have introduced a bias, even though there was no significant difference in clinical outcome between the two centers. The NT-ProBNP blood samples were drawn in an ambulatory setting with the patient in stable cardiac condition, but the patient's clinical status was not evaluated at the same day, and therefore a potential confounding of results due to intermittent fluid overload or concurrent infection etc. cannot be ruled out. The percentage of women in this study was relatively low, which affects the generalizability of the results to women with HF. The cluster of risk factors called metabolic syndrome has also been suggested as a prognostic factor for CRT patients, but unfortunately we were not able to investigate this since our data did not include incidence of the metabolic syndrome. No continuous remote monitoring of the patients was performed during the follow up period.

\section{Conclusion}

Post-implant changes in NT-proBNP correlate with echocardiographic and clinical response to CRT. By using a combined "CRT response score", consisting of echo-, clinical-, and biochemical response criteria, 3-year clinical outcome can be predicted with higher accuracy. This information may be particularly helpful for a better identification of non-responders with poor clinical outcome, and could direct attention to the patients in need of a reintervention or modification of relevant CRT-related parameters.

\section{Additional file}

Additional file 1: Figure S1. ROC analysis for change in NT- proBNP vs. freedom from composite endpoint at 3 years. (JPEG $1805 \mathrm{~kb}$ )

\footnotetext{
Abbreviations

ACEi: Angiotensin converting enzyme inhibitor; AF: Atrial fibrillation; ARB: Angiotensin receptor blocker; BNP: Brain natriuretic peptide; CABG: Coronary artery bypass surgery; CRT: Cardiac Resynchronization therapy; CRT-D: Cardiac Resynchronization therapy with defibrillator function; CRT-P: Cardiac Resynchronization therapy without defibrillator function; CS: coronary sinus; EF: Ejection fraction; HR: Hazard ratio; LBBB: Left bundle branch block; LV: Left ventricle; LVAD: Left ventricular assist device; LVEDD: Left Ventricular end diastolic diameter; LVEDV: Left Ventricular end diastolic volume; LVESV: Left Ventricular end systolic volume; LVESVi: Left Ventricular end systolic volume index; NT-proBNP: N terminal pro Brain Natriuretic Peptide; NYHA: New York Heart Association; RV: Right ventricle
} 


\section{Acknowledgements}

We would like to thank to our colleagues for the help we received and all the participants for their contributions.

\section{Funding}

No funding was received for this study.

\section{Availability of data and materials}

The data that support the findings of this study are available from the Skane University Hospital in Lund, but restrictions apply and thus are not publicly available. However, the data are available from the authors upon reasonable request and with permission from Skane University Hospital and Massachusetts General Hospital.

\section{Authors' contributions}

All of the authors were actively involved in this trial. B Z, R C and B R collected the data from the Swedish site, while data from the US site were collected by $C N C$ and S JP. Data analysis was performed by Z B and R B. Manuscript was drafted by B Z and B R. C NC and S JP critically revised the manuscript for important intellectual content. All authors read and approved the final manuscript.

\section{Ethics approval and consent to participate}

All participants provided written consent before entering the study. Approval was obtained from the Regional ethics review board in Lund, Sweden (Skane University Hospital, Lund) and Institutional Review Board at Massachusetts General Hospital in Boston, USA respectively.

\section{Consent for publication}

Not applicable.

\section{Competing interests}

The authors declare that they have no competing interests.

\section{Publisher's Note}

Springer Nature remains neutral with regard to jurisdictional claims in published maps and institutional affiliations.

Received: 13 November 2017 Accepted: 4 April 2018

Published online: 24 April 2018

\section{References}

1. Tang ASL, Wells GA, Talajic M, Arnold MO, Sheldon R, Connolly S, et al. Cardiac-resynchronization therapy for mild-to-moderate heart failure. N Engl J Med. 2010;363:2385-95.

2. Moss AJ, Hall WJ, Cannom DS, Klein H, Brown MW, Daubert JP, et al. Cardiac-resynchronization therapy for the prevention of heart-failure events. N Engl J Med. 2009:361(14):1329-38.

3. Cleland JG, Daubert JC, Erdmann E, Freemantle N, Gras D, Kappenberger L, et al. The effect of cardiac resynchronization on morbidity and mortality in heart failure. N Engl J Med. 2005;352(15):1539-49.

4. Bristow MR, Saxon LA, Boehmer J, Krueger S, Kass DA, De Marco T, et al. Cardiac-resynchronization therapy with or without an implantable defibrillator in advanced chronic heart failure. N Engl J Med. 2004; 350(21):2140-50.

5. Gorcsan J 3rd. Finding pieces of the puzzle of nonresponse to cardiac resynchronization therapy. Circulation. 2011;123(1):10-2.

6. Ng CY, Heist EK. Cardiac Resynchronization Therapy: Maximizing the Response to Biventricular Pacing. Cardiol Rev. 2017;25(1):6-11. Review.

7. Boerrigter G, Costello-Boerrigter LC, Abraham WT, St. John Sutton MG Heublein DM, Kruger KM, et al. Cardiac resynchronization therapy improves renal function in human heart failure with reduced glomerular filtration rate. J Card Fail. 2008;14:539-46.

8. Venkateswaran RV, Freeman C, Chatterjee N, Kandala J, Orencole M, Vegh EM, et al. Anemia and its association with clinical outcome in heart failure patients undergoing cardiac resynchronization therapy. J Interv Card Electrophysiol. 2015;44(3):297-304.

9. Sardu C, Santamaria M, Funaro S, Sacra C, Barbieri M, Paolisso P, et al. Cardiac electrophysiological alterations and clinical response in cardiac resynchronization therapy with a defibrillator treated patients affected by metabolic syndrome. Medicine (Baltimore). 2017;96(14):e6558.
10. Sardu C, Barbieri M, Santamaria M, Giordano V, Sacra C, Paolisso P, et al. Multipolar pacing by cardiac resynchronization therapy with a defibrillators treatment in type 2 diabetes mellitus failing heart patients: impact on responders rate, and clinical outcomes. Cardiovasc Diabetol. 2017;16(1):75.

11. Mullens W, Grimm RA, Verga T, Dresing T, Starling RC, Wilkoff BL, et al. Insights from a cardiac resynchronization optimization clinic as part of a heart failure disease management program. J Am Coll Cardiol. 2009; 53(9):765-73.

12. Altman RK, Parks KA, Schlett CL, Orencole M, Park MY, Truong QA, et al. Multidisciplinary care of patients receiving cardiac resynchronization therapy is associated with improved clinical outcomes. Eur Heart J. 2012;33(17):2181-8

13. Boidol J, Sredniawa B, Kowalski O, Szulik M, Mazurek M, Sokal A, et al. Many response criteria are poor predictors of outcomes after cardiac resynchronization therapy: validation using data from the randomized trial. Europace. 2013;15(6):835-44.

14. Fornwalt BK, Sprague WW, BeDell P, Suever JD, Gerritse B, Merlino JD, et al. Agreement is poor among current criteria used to define response to cardiac resynchronization therapy. Circulation. 2010;121(18):1985-91.

15. Brenyo A, Barsheshet A, Rao M, Huang DT, Zareba W, McNitt S, et al. Brain natriuretic peptide and cardiac resynchronization therapy in patients with mildly symptomatic heart failure. Circ Heart Fail. 2013;6(5): 998-1004.

16. Delgado RM, Palanichamy N, Radovancevic R, Vrtovec B, Radovancevic B. Brain natriuretic peptide levels and response to cardiac resynchronization therapy in heart failure patients. Congest Heart Fail. 2006;12(5):250-3.

17. Sardu C, Marfella R, Santulli G, Paolisso G. Functional role of miRNA in cardiac resynchronization therapy. Pharmacogenomics. 2014;15(8): 1159-68.

18. TheTask Force on cardiac p, resynchronization therapy of the European Society of Cardiology . Developed in collaboration with the European Heart Rhythm A, Brignole M, Auricchio A, Baron-Esquivias G, Bordachar P, et al. ESC guidelines on cardiac pacing and cardiac resynchronization therapy. Rev Esp Cardiol (Engl Ed) 2014. 2013;67(1):58.

19. Epstein AE, DiMarco JP, Ellenbogen KA, Estes NA 3rd, Freedman RA, Gettes LS, et al. ACC/AHA/HRS 2008 guidelines for device-based therapy of cardiac rhythm abnormalities: a report of the American College of Cardiology/ American Heart Association Task Force on Practice Guidelines (writing committee to revise the ACC/AHA/NASPE 2002 guideline update for implantation of cardiac pacemakers and Antiarrhythmia devices): developed in collaboration with the American Association for Thoracic Surgery and Society of Thoracic Surgeons. Circulation. 2008;117(21):e350-408.

20. Doltra A, Bijnens B, Tolosana JM, Borras R, Khatib M, Penela D, et al. Mechanical abnormalities detected with conventional echocardiography are associated with response and midterm survival in CRT. JACC CardiovasC Imaging. 2014;7(10):969-79.

21. Bilchick KC, Stukenborg GJ, Kamath S, Cheng A. Prediction of mortality in clinical practice for medicare patients undergoing defibrillator implantation for primary prevention of sudden cardiac death. J Am Coll Cardiol. 2012; 60(17):1647-55

22. Biton Y, Zareba W, Goldenberg I, Klein H, McNitt S, Polonsky B, et al. Sex differences in long-term outcomes with cardiac resynchronization therapy in mild heart failure patients with left bundle branch block. J Am Heart Assoc. 2015:4(7)

23. Goldenberg I, Vyas AK, Hall WJ, Moss AJ, Wang H, He H, et al. Risk stratification for primary implantation of a cardioverter-defibrillator in patients with ischemic left ventricular dysfunction. J Am Coll Cardiol. 2008; 51(3):288-96.

24. Zhang Q, Zhou Y, Yu CM. Incidence, definition, diagnosis, and management of the cardiac resynchronization therapy nonresponder. Curr Opin Cardiol. 2015:30(1):40-9.

25. Bordachar P, Eschalier R, Lumens J, Ploux S. Optimal strategies on avoiding CRT nonresponse. Curr Treat Options Cardiovasc Med. 2014;16(5):299.

26. Solomon SD, Foster E, Bourgoun M, Shah A, Viloria E, Brown MW, et al. Effect of cardiac resynchronization therapy on reverse remodeling and relation to outcome: multicenter automatic defibrillator implantation trial: cardiac resynchronization therapy. Circulation. 2010;122(10):985-92.

27. Ge Y, Ruwald AC, Kutyifa V, McNitt S, Polonsky S, Klein H, et al. A metric for evaluating the cardiac response to resynchronization therapy. Am J Cardiol. 2014;113(8):1371-7. 
28. St John Sutton M, Ghio S, Plappert T, Tavazzi L, Scelsi L, Daubert C, et al. Cardiac resynchronization induces major structural and functional reverse remodeling in patients with New York Heart Association class 1/II heart failure. Circulation. 2009;120(19):1858-65.

29. Gold MR, Daubert C, Abraham WT, Ghio S, St John Sutton M, Hudnall JH, et al. The effect of reverse remodeling on long-term survival in mildly symptomatic patients with heart failure receiving cardiac resynchronization therapy: results of the REVERSE study. Heart Rhythm. 2014;

30. Linde C, Gold MR, Abraham WT, St John Sutton M, Ghio S, Cerkvenik J, et al. Long-term impact of cardiac resynchronization therapy in mild heart failure: 5-year results from the REsynchronization reVErses remodeling in systolic left vEntricular dysfunction (REVERSE) study. Eur Heart J. 2013;34(33):2592-9.

31. Packer M. Proposal for a new clinical end point to evaluate the efficacy of drugs and devices in the treatment of chronic heart failure. J Card Fail. 2001:7(2):176-82.

32. Abraham WT, Hayes DL. Cardiac resynchronization therapy for heart failure. Circulation. 2003;108(21):2596-603.

33. Young JB, Abraham WT, Smith AL, Leon AR, Lieberman R, Wilkoff B, et al. Combined cardiac resynchronization and implantable cardioversion defibrillation in advanced chronic heart failure: the MIRACLE ICD trial. JAMA. 2003;289(20):2685-94.

34. Reitan C, Bakos Z, Platonov PG, Hoijer CJ, Brandt J, Wang L, et al. Patient-assessed short-term positive response to cardiac resynchronization therapy is an independent predictor of long-term mortality. Europace. 2014;16(11):1603-9.

35. Oremus M, Don-Wauchope A, McKelvie R, Santaguida PL, Hill S, Balion C et al. BNP and NT-proBNP as prognostic markers in persons with chronic stable heart failure. Heart Fail Rev. 2014;19(4):471-505.

36. Santaguida PL, Don-Wauchope AC, Oremus M, McKelvie R, Ali U, Hil SA, et al. BNP and NT-proBNP as prognostic markers in persons with acute decompensated heart failure: a systematic review. Heart Fail Rev. 2014;19(4):453-70.

37. Shalaby AA, Abraham WT, Fonarow GC, Bersohn MM, Gorcsan J 3rd, Lee LY, et al. Association of BNP and troponin levels with outcome among cardiac resynchronization therapy recipients. Pacing Clin Electrophysiol. 2015;38(5):581-90.

38. Berger R, Shankar A, Fruhwald F, Fahrleitner-Pammer A, Freemantle N, Tavazzi $L$, et al. Relationships between cardiac resynchronization therapy and $N$ terminal pro-brain natriuretic peptide in patients with heart failure and markers of cardiac dyssynchrony: an analysis from the Cardiac Resynchronization in Heart Failure (CARE-HF) study. Eur Heart J. 2009;30(17):2109-16.

39. Brouwers C, Versteeg H, Meine M, Heijnen CJ, Kavelaars AM, Pedersen SS, et al. Association between brain natriuretic peptide, markers of inflammation and the objective and subjective response to cardiac resynchronization therapy. Brain Behav Immun. 2014;40:211-8.

40. Fruhwald FM, Fahrleitner-Pammer A, Berger R, Leyva F, Freemantle N,

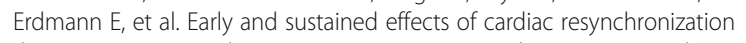
therapy on $\mathrm{N}$-terminal pro-B-type natriuretic peptide in patients with moderate to severe heart failure and cardiac dyssynchrony. Eur Heart $\mathrm{J}$. 2007;28(13):1592-7.

41. Braun MU, Rauwolf T, Zerm T, Schulze M, Schnabel A, Strasser RH. Long term biventricular resynchronisation therapy in advanced heart failure: effect on neurohormones. Heart. 2005;91(5):601-5.

42. Seifert M, Schlegl M, Hoersch W, Fleck E, Doelger A, Stockburger M, et al. Functional capacity and changes in the neurohormonal and cytokine status after long-term CRT in heart failure patients. Int J Cardiol. 2007;121(1):68-73.

43. Kubanek M, Malek I, Bytesnik J, Fridl P, Riedlbauchova L, Karasova L, et al. Decrease in plasma B-type natriuretic peptide early after initiation of cardiac resynchronization therapy predicts clinical improvement at 12 months. Eur J Heart Fail. 2006;8(8):832-40

44. Pitzalis MV, lacoviello M, Di Serio F, Romito R, Guida P, De Tommasi E, et al. Prognostic value of brain natriuretic peptide in the management of patients receiving cardiac resynchronization therapy. Eur J Heart Fail. 2006;8(5):509-14.

45. Sardu C, Marfella R, Santulli G. Impact of diabetes mellitus on the clinical response to cardiac resynchronization therapy in elderly people. J Cardiovasc Transl Res. 2014;7(3):362-8.

46. Min X, Meine M, Baker JH 2nd, Pires LA, Turk KT, Horn EM, et al. Estimation of the optimal $\mathrm{W}$ delay by an IEGM-based method in cardiac resynchronization therapy. Pacing Clin Electrophysiol. 2007;30(Suppl 1):S19-22.

\section{Ready to submit your research? Choose BMC and benefit from:}

- fast, convenient online submission

- thorough peer review by experienced researchers in your field

- rapid publication on acceptance

- support for research data, including large and complex data types

- gold Open Access which fosters wider collaboration and increased citations

- maximum visibility for your research: over $100 \mathrm{M}$ website views per year

At BMC, research is always in progress.

Learn more biomedcentral.com/submissions 